\title{
Pembangunan Generasi Berkarakter Rabbany Melalui Internalisasi Nilai- Nilai Ibadah Mahdlah di Kabupaten Cianjur
}

\author{
Sofyan Sauri ${ }^{1 *}$, Asep Sopian ${ }^{1}$ \\ ${ }^{\mathbf{1} D e p a r t e m a n ~ P e n d i d i k a n ~ B a h a s a ~ A r a b, ~ F a k u l t a n ~ P e n d i d i k a n ~ B a h a s a ~ d a n ~ S a s t r a ~}$ \\ Universitas Pendidikan Indonesia \\ *Penulis Korespondensi, Sofyan Sauri Departemen Pendidikan Bahasa Arab FPBS Universitas Pendidikan \\ Indonesia 40151. Email: sofyansauri@upi.edu
}

\begin{abstract}
ABSTRAK
Fenomena yang terjadi pada saat ini menunjukkan keterpurukan moral dan akhlak manusia. Beritaberita pembunuhan, pemerkosaan, perzinahan, perjudian, perampokan, dan lain sebagainya sudah menjadi menu berita setiap pagi. Belum lagi, sarana yang mempermudah akses manusia terhadap berbagai hal yang mengarah kepada dekadensi moral semakin mudah di antaranya dengan adanya internet dan hand phone. Seorang siswa dapat dengan mudah mengunduh video porno yang baru-baru ini dilakukan dan dipertontonkan oleh para artis. Di samping itu, berbagai berita dalam masalah hukum seperti parade pemberitaan tentang koruptor, mulai dari pengusaha sampai pejabat baik eksekutif, yudikatif, maupun legislatif. Kegiatan ini bertujuan memberikan pengetahuan dan penyadaran kepada masyarakat tentang urgensi membangun masyarakat rabbany melalui internalisasi nilai-nilai ibadah mahdlah, disamping sebagai sarana penerapan ilmu keagamaan. Metode kegiatan ini dilakukan melalui seminar dan penyuluhan serta pendampingan di Desa Cidadap Kabupaten Cianjur dengan sasaran majelis taklim, ormas, pada dai, dan guru. Adapun kesimpulan bahwa internalisasi pendidikan karakter berbasis nilainilai ibadlah mahdlah sangat penting dalam membangun generasi rabbany.
\end{abstract}

Kata kunci: Generasi Berkarakter, Internalisasi Nilai-Nilai, Ibadah Rabbani

\begin{abstract}
At this time, the trend demonstrates the weakening of human morals and morality. Each morning news of assassination, murder, adultery, gambling, theft, and so on has become a news list. Not to mention, the facilities with internet and mobile phones that facilitate human access to various things that lead to moral decadence are becoming increasingly simple. A student can easily download videos of pornography that artists have recently made and shown. Further more, various legal news such as the corruptors news show, ranging from businessmen to president, judici ary, and legislative officials. This project seeks to provide the public with knowledge and awareness of the importance of creating a rabbany community by internalizing worship mahdlah principles, as well as being a way of applying religious knowledge. The method of this operation is carried out through seminars and guidance, as well as mentoring in Cidadap Village, Cianjur Regency with the goal of majelis taklim, mass organizations, preachers and teachers. The conclusion is that internalizing character education based on the values of ibadah is very important in developing a generation of rabbany
\end{abstract}

Keywords: Generation of character, Values internalization, Rabbany worship

PENDAHULUAN

Analisis Situasi

Pembangunan Sumber Daya Manusia

(SDM) merupakan suatu keniscayaan. Bahkan ia merupakan fondasi pembangunan bangsa. Abad ke-21 ini membutuhkan SDM yang berkualitas secara karakter, kemampuan literasi, kemampuan 4C, yakni Communication, Collaboration, Critical Thinking and Problem Solving, dan Creativity and Innovation agar Indonesia dapat bersaing dengan bangsa bangsa lain. 
Pada kenyataannya, Pendidikan dewasa ini lebih banyak difokuskan pada capaian capain kognitif semata. Para orang tua amat senang bila akannya meraih nilai, namun tidak sedikit yang tidak memperhatikan karakter. Hal ini diduga keras menimbulkan persoalan karakter, dekadensi dan degradasi moral, etika, dan budi pekerti.

Fenomena yang terjadi pada saat ini menunjukkan keterpurukan moral dan akhlak. Kemenpora RI (2009) menyajikan berbagai kenakalan remaja sebagai berikut. Polri telah mengelompokkan tujuh belas jenis gangguan Kamtibnas sebagai Peristiwa Penting Gangguan Kamtibnas (PPGK) Khusus. Ketujuhbelas jenis gangguan yang dimaksud adalah sara, pemogokan, unjuk rasa, Curanmor roda 2, Curanmor roda 4, pencurian kawat telepon, pencurian kayu, pencurian dengan senpi, pencurian dengan senjata tajam, pembajakan, kenakalan remaja, perkelahian TNI/Polri, perkara koneksitas, Laka Lantas korban mati, laka kereta api korban mati, laka laut korban mati, dan laka udara korban mati dengan jumlah kejadian yang terjadi pada tahun 2008 sebanyak 53.071 peristiwa.

Tafsir (2000: 3) pernah menyitir tentang dunia pendidikan di Indonesia. Lihat!, ”Apa yang terjadi hari-hari ini. Mulai dari korupsi yang dilakukan tanpa rasa malu, kesewenangan, narkoba, pelacuran dan perselingkuhan, ketidakkonsistenan dalam sikap, perkelahian antarsiswa sekolah, pertempuran antarwarga kampung, penjarahan dan sebagainya, dan lihat pula krisis yang sedang kita alami sekarang, sebenarnya ada kekeliruan dalam pendidikan kita. Bukan saja sejak Orde Baru, melainkan sejak kemerdekaan, dan sampai hari ini pendidikan kita masih keliru. Kekeliruan itu terletak pada pandangan yang masih keliru tentang posisi pendidikan Agama (pendidikan keimanan). Pendidikan kita belum pernah menjadikan pendidikan keimanan itu sebagai inti (core) kurikulum pendidikan.
Kecemasan berbagai kalangan tentang kondisi pendidikan di lingkungan terdekatnya menunjukkan pendidikan yang sudah kehilangan karakter. Beberapa data dapat digunakan untuk menggambarkan bahwa betapa dekadensi moral dan karakter buruk yang ditunjukkan siswa merupakan contoh bagian yang tidak terpisahkan dalam dunia pendidikan kita saat ini.

Berbagai permasalahan bangsa sebagaimana disebutkan di atas harus segera diakhiri. Sejatinya semua pihak perlu introspeksi diri, segera mencari solusi jitu dan terlibat secara intensif. Salah satu solusi yang sangat tepat adalah dengan optimalisasi penerapan pendidikan karakter di sekolah menengah. Pola pendidikan saat ini hanya menghasilkan siswayang kehilangan kepekaan sosial (sence of social crisis) atau kehilangan kasadaran budi nurani manusia (social consciousness of men). Siswa hanya memiliki kemampuan teknis (skill) dan menjadi manusia "siap pakai" layaknya robot (Ghopur, 2010). Akibat yang ditimbulkan cukup serius dan tidak dapat lagi dianggap sebagai suatu persoalan sederhana

Banyak orang berpandangan bahwa kondisi demikian diduga berawal dari apa yang dihasilkan oleh dunia pendidikan. Dunia pendidikan, sesungguhnya memberikan kontribusi paling besar terhadap situasi ini. Dalam konteks pendidikan formal di sekolah, salah satu penyebabnya karena pendidikan di Indonesia lebih menitikberatkan pada pengembangan intelektual semata. Aspek-aspek lain yang ada dalam diri siswa, yaitu aspek afektif dan kebajikan moral kurang mendapatkan perhatian

Oleh karena itu, pendidikan karakter sangat diperlukan di tengah kemajuan yang luar biasa dalam bidang ilmu pengetahuan dan teknologi saat ini tidak mendorong manusia untuk lebih meyakini Tuhannya, apalagi mengamalkan ajarannya. Yang terjadi adalah manusia menjadikan IPTEK laksana tuhan dan agama mulai ditinggalkan. Hal ini tidak terlepas dari pengaruh filsafat positivisme, rasionalisme, 
dan materialisme. Begitu pula dalam urusan pendidikan. Dasar-dasar filsafat tersebut dikembangkan dan diaplikasikan oleh paradigma behaviorisme yang tidak memberikan ruang untuk mengembangkan aspek akhlak manusia secara utuh. Aspek-aspek ruh hampir tidak tersentuh, padahal ia merupakan aspek yang esensial bagi kehidupan manusia.

Komalasari (2012) dalam Asia Pacific Journal of Educators and Education, Vol. 27, 87-103, 2012 menulis artikel penelitian berjudul the effect of contextual learning in civic education on students' character development. Dalam artikel ini, dia menyimpulkan bahwa "that first, contextual learning in civic education taught student's life skills, including the principles of interdependence, differentiation, and self-regulation; second, contextual learning in civic education encouraged the establishment of democratic learning; third, contextual learning in civic education includes elements of character development; and fourth, character education in civic education helped students discover and develop local moral values".

Senada dengan pendapat di atas, Setyaningrum dan Husamah (2010) dalam penelitian berjudul optimalisasi penerapan pendidikan karakter di sekolah enengah berbasis keterampilan proses di antaranya menyimpulkan: 1) Karakter mencakup pengertian, kepedulian, dan tindakan berdasarkan nilai-nilai etika, meliputi aspek kognitif, emosional, dan perilaku dari kehidupan moral. Karakter terbentuk dengan dipengaruhi oleh paling sedikit 5 faktor, yaitu: temperamen dasar, keyakinan, wawasan,motivasi hidup dan perjalanan. Karakter yang dapat membawa keberhasilan yaitu empati, tahan dan beriman. 2) Pendidikan karakter adalah pendidikan budipekerti plus, yaitu yang melibatkan aspek pengetahuan (cognitive), perasaan (feeling), dan tindakan (action). Pendidikan karakter merupakan berbagai usaha yang dilakukan oleh para personil sekolah, bahkan yang dilakukan bersama-sama dengan orang tua dan anggota masyarakat, untuk membantu siswa agar menjadi atau memiliki sifat peduli, berpendirian, dan bertanggung jawab.

Uraian di atas menunjukkan betapa pentingnya upaya positif dalam membangung karakter, yakni dengan kerjasama dengan majelis taklim dan organasasi kepemudaan yang ada di Cidadap Kabupaten Cianjur.

\section{Tujuan dan Manfaat Kegiatan}

Kegiatan pengabdian ini hendak mengaplikasikan bidang ilmu agam dan pendidikan Nilai. Selaras dengan analisis situasi, kegiatan ini bertujuan:

a) memberikan pengetahuan dan penyadaran akan urgensi membangun masyarakat Rabbani

b) memberikan pengetahuan dan penyadaran tentang konsep dan model internalisasi nilai Ibadah mahdlah di tengah-tengah tantangan zaman yang semakin komplek, terutama meningkatnya dekadensi moral di berbagai daerah.

\section{METODE PELAKSANAAN}

\section{Sasaran kegiatan}

Sasaran pelaksanaan kegiatan penyuluhan ini adalah para aktivis majelis taklim, organisasni pemuda, guru, dan orang tua. Adapun yang hadir pada kegiatan ini berjumlah 50 orang.

\section{Lokasi kegiatan}

Pengabdian ini dilaksanakan di di Desa Cidadap Kecamatan Campana Kabupaten Cianjur Jawa Barat .

\section{Metode yang digunakan}

Dalam kegiatan ini diterpakan metode sebagai berikut:

a) Penyuluhan kepada khalayak sasaran (majelis taklim, organisasi pemuda, guru, dan orang 
tua) tentang urgensi membangun generasi rabbany

b) Penyuluhan kepada khalayak sasaran (majelis taklim, organisasi pemuda, guru, dan orang tua) tentang konsep dan model internalisasi nilai-nilai ibadah mahdlah.

c) Sharing dengan khalayak sasaran berkaitan dengan aktivitas pendidikan karakter sesuai dengan profesi masing-masing.

d) Pembagian angket yang terdiri dari 28 pertanyaan (yang dikategorikan dalam 5 karakter utama, yakni nasionalisme, kemandirian, religious, gotong-royong, dan integritas) berkaitan dengan internaliassi yang dilakukan khalayak sasaran.

e) Melakukan evaluasi kegiatan pengabdian melalui angket.

\section{HASIL DAN PEMBAHASAN}

Pendidikan karakter berbasis nilai - nilai ibadah salat maksudnya pendidikan karakter yang berlandaskan nilai - nilai yang digali dari praktik ibadah salat. Diantara nilai itu adalah perilaku hidup bersih, disiplin, toleran, kerjasama/organisasi, hidup sehat jsmani dan ruhani, demokratis.

Nilai - nilai di atas selaras degan paparan Puskur Depdiknas tahun 2010 dan GNRM tahun 2014 yang dikutip Hendarman (2016) berikut.

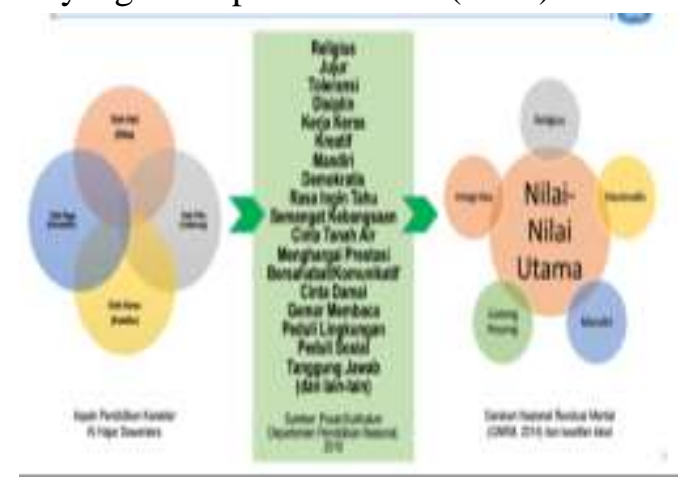

Gambar 1

Nilai - Nilai Karakter Utama Bangsa Indonesia

Dari bagan di atas, dapat dikatakan bahwa SDM abad ke-21 mesti memiliki karakter sebagai berikut.
1. Religius, yakni SDM yang mempercayai dan mengimani serta melaksanakan perintah Tuhan dan menjauhi laranganNya.

2. Integritas, yakni SDM yang memiliki komitmen, jujur, dapat dipercaya, bertanggung jawab, memiliki loyalitas, konsisten, disiplin, dan berkualitas,

3. Gotong royong, yakni SDM yang tidak soliter, yang mampu hidup berdampingan dan bekerjasama, toleran, dan mampu berorganiasi.

4. Mandiri, yakni SDM yang mampu berdiri di atas kaki sendiri, tidak menjadi benalu, mempu menghidupi diri sendiri, dan melakukan aktivitas pokok sendiri.

5. Nasionalis, yakni SDM yang memiliki jiwa patriotism, mencintai, dan membela keutuhan Negara di antaranya dengan menjadi orang yang bermanfaat bagi sesama.

Secara umum para peserta sudah memahami dan mengalami peningkatan dalam pemahaman dasar urgensi pendidikan karakter dalam membangun generasi Rabbani melalui internalisasi nilai-nilai ibadah mahdlah. Yang selanjutnya, dilakukan melalui model internalisasi menurut Sopian (2018) berikut:

Pertama, Sosialisasi, maksudnya pendidik/orang tua/masyarakat/pemerintah memberitahukan secara massif nilai - nilai dan karakter yang hendak diterapkan dan diinternaslisasikan kepada stake holder.

Sosialisasi merupakan salah satu aspek penting dalam proses kontrol sosial dalam hal ini pendidikakan karakter sebab untuk dapat mempengaruhi orang-orang agar bertingkah laku sesuai dengan nilai - nilai yang berlaku, dibutuhkan suatu sarana yang timbul dalam diri seseorang untuk mentaati dan melaksanakan nilai - nilai karakter. Pada gilirannya, siswa memiliki kesadaran untuk melakukan aneka karakter yang baik. 
Pada kenyataannya, kesadaran untuk melakukan suatu yang baru tidak tumbuh dengan sendirinya pada diri seseorang, tetapi perlu adanya suatu proses yang tidak pendek untuk menumbuhkannya. Kesadaran tersebut dapat ditumbuhkan melalui berbagai cara seperti pengkhabaran, pemberitahuan, pendidikan, maupun pengajaran. Melalui cara-cara tersebut diharapkan seseorang akan menjadi tau mengenai apa isi normatif yang terkandung dalam nilai - nilai pendidikan karakter ada. Kemudian setelah seseorang tahu, ia akan berusaha berusaha menyesuaikan segala perilakunya nilai - nilai karakter tersebut.

Selanjutnya proses tersebut biasanya akan berlanjut pada proses pembangkitan rasa patuh dan setia yang tidak hanya menanamkan pengetahuan baru (kognisi) saja tetapi dengan proses ini akan menggugah perasaan (afeksi) pada diri seseorang yang akan menumbuhkan dan membentuk sikap positif yakni rasa taat yang ikhlas. Kesemua proses tersebut diataslah yang disebut sebagai proses sosialisasi.

Kedua, teaching and learning, maksudnya nilai - nilai karakter diajarkan secara sestematis formal di berbagai lingkungan, misalnya diajarkan kepada siswa di sekolah lalu diobservasi dan dievaluasi serta diberikan reward and punishment. Allah ta'ala berfirman,

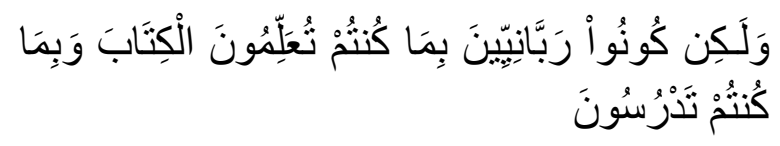
.... akan tetapi jadilah kalian generasi Rabbani dengan senaniasa mengajarkan Alquran dan mempelajarinya. (QS. Ali Imran, 79).

Generasi Rabbani adalah generasi yang memiliki karakter. Yakni berilmu, penyayang, taat ibadah, fakih, pendidik, dan berswawasan. Berkaitan dengan pembelajaran ini, Allah Ta'ala berfiman,

Dia mengajarkan manusia apa yang tidak diketahuinya (QS. al-`Alaq [96]: 5).
Dan dia mengajarkan kepada Adam namanama (benda-benda) seluruhnya . . . (QS. alBaqarah [2]: 31)

Proses teaching and learning ini dapat dilakukan melalui:

1. tilawah ayat, yakni membaca ayat - ayat Alquran

2. tazkiyah nafs, yakni penyucian diri agar peserta didik mau menerima pembelajaran

3. ta'lim kitab wal hikmah, yakni mengajarkan ayat - ayat, mengambil hikmah, dan nilai - nilai karkter.

Ketiga, habituation. Selain dua proses internalisasi di atas, dilakukan pembiasaan yang massif dan terus menerus sampai menjadi sebuah kebiasaan, adat istiadat, budaya, dan karakter diri. Tahap ini sangat diperlukan konsistensi dari para pendidik/orang tua/masyarakat/pemerintah. Sesuatu yang sudah biasa dilakukan akan sangat sulit ditinggalkan. Apabila yang dibiasakan hal yang baik dan positik sejak dini, maka ia akan terus dialakukan sampai dewasa bahkan sampai usia senja. Allah Ta'ala berfirman,

Hai orang-orang yang beriman, hendaklah budak-budak (lelaki dan wanita) yang kamu miliki dan orang-orang ayang belum baligh diantara kamu, meminta izin kepadamu tiga kali (dalam satu hari) yaitu: sebelum sembahyang subuh, ketika kamu meninggalkan pakaian (luar) mu ditengah hari, dan sesudah sembahyang isya, (itulah) tiga aurat bagi kamu (QS.al-Nǔr [24]: 58).

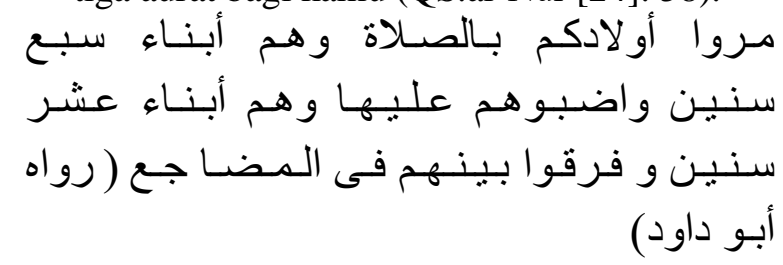

Surulah anak-anak kalian untuk melaksanakan shalat ketika mereka berumur tujuh tahun, dan pukullah mereka apabila meninggalkannya ketika mereka berumur sepuluh tahun, dan pisahkanlah tempat tidur mereka" (H.R..Abǔ Dawǔd). 
Secara lebih jelas proses pembiasaan dan pembudayaan pendidkan karakter di sekolah dapat disajikan pada gambar di bawah ini.

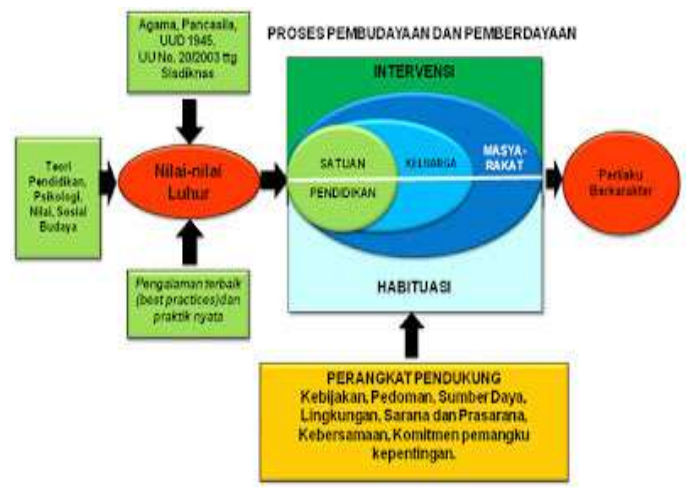

Gambar 2. Skema Proses Pembudayaan dan Pemberdayaan Pendidikan Karakter (Susmanto, 2012)

Dari gambar di atas, sangatlah jelas pembiasaan itu dilakukan mulai dari sekolah, keluarga dan masyarakat. Hal ini akan berlangsung dengan baik dengan dukungan kebijakan pemerintah dan stakeholder lainya.

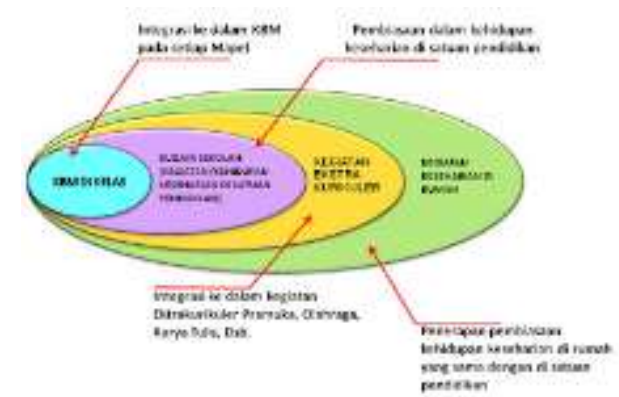

Gambar 3 Skema Strategi Mikro Pembiasaan Pendidikan Karakter di Sekolah (Susmanto, 2012)

Dari gambar di atas, dapat dinyatakan bahwa pembiasaan yang dilakukan dalam berbagai lingkungan, yakni di dalam kelas melalui KBM secara integrative masuk ke dalam setiap mata pelajaran, dalam kehidupan keseharian di sekolah/satuan penddikan, kegiatan ekstrakurikuler, dan di rumah agar pembiasaan yang diterapkan di sekolah diterapkan juga di rumah.

Keempat, role model. Tahap ini tidak kalah pentingnya. Sebab melalui tahap ini peserta didik akan melihat model dan contoh dari pendidik/orang tua/masyarakat/pemerintah dalam melaksakanan berbagai nilai dan karakter. Dan peneliti berkeyakinan bahwa tahap inilah yang memiliki pengaruh sangat kuat dalam internalisasi karakter pada peserta didik. Hal ini selaras dengan Firman Allah Ta'ala,

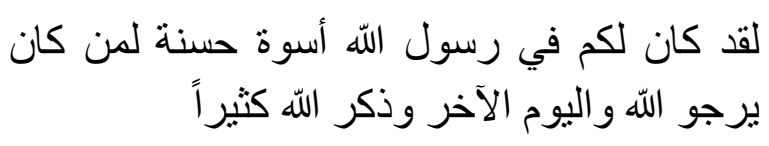

Sunggguh dalam diri Rasulullah terdapat teladan yang baik bagi siapa saja yang mengharapkan Allah dan hari Akhir serta banyak berdzikir kepada Allah (QS. Al-Ahzab, 21)

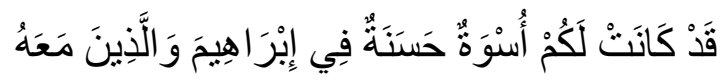

Sungguh pada diri Ibrahim dan orang orang yang bersamanya terdapat teladan yang baik bagi kalian (QS. Al-Mumtahanah, 3)

Tanpa adanya keteladanan keteladanan, sangat kecil kemungkinan internalisasi pendidikan karakter ini dapat terwujud dengan optimal. Sebab peserta didik akan melihat dan mencontoh keseharian para pendidiknya.

Setelah melakukan diskusi dan pendampingan, para peserta mengisi angket yang telah disediakan. Data yang diperoleh sebagai berikut.

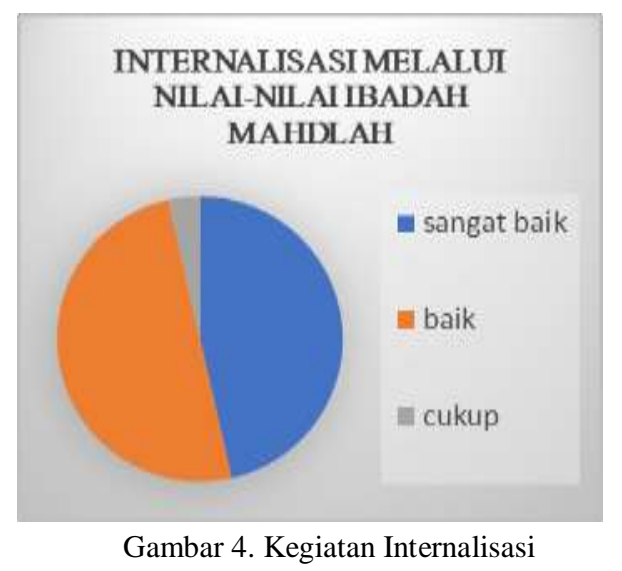

Berdasarkan gambar di atas, para guru, dai, dan orang tua telah melakukan internalisasi 
pendidika karakter dengan sangat baik (46\%), baik (50\%), dan cukup (4\%). Dengan demikian merka telah melakukan tugas internaliasi dengan maksimal.

Adapun jika dikateorikan menjadi 5 karakter utama,yakni Religius, integritas, mandiri, kerjasama, dan nasionalisme tampak pada gambar berikut.

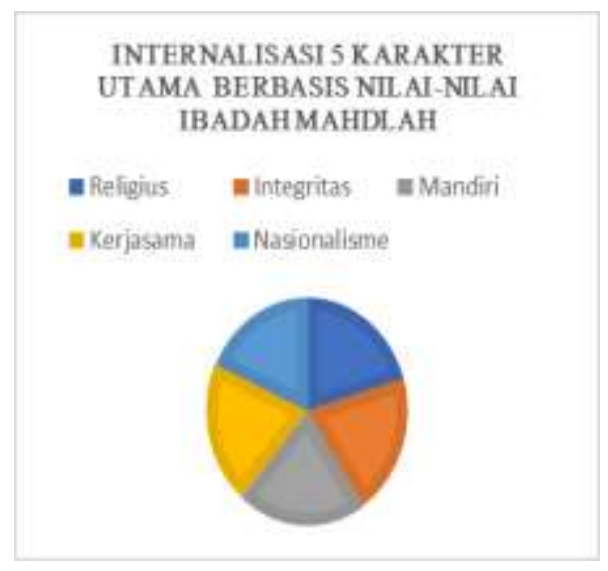

Gambar 5 Internalisasi 5 karater utama berbasis nilai-nilai ibadah

Dari gambar di atas, sangat jelas bahwa proses internaliasi yang dilakukan guru,dai,dan orang tua di desa Cidadap KAbupaten Cianjur dalam kategori baik semua, kecuali aspek nasionalisme. Secara rinci aspek religious (83.17), integritas (82.52), mandiri(84.26), dan nasionalisme $(74,26)$.

Walaupun sudah baik, aspek karakter nasionalisme masih perlu ditingkatkan lagi

\section{KESIMPULAN DAN SARAN}

Berdasarkkan hasil dan pembahasan disimpulkan bahwa kegiatan penyuluhan ini sangat diperlukan dan dibutuhkan berbagai khalayak sasaran (majelis taklim, organisasi pemuda, guru, dan orang tua). Merekalah yang menjadi ujung tombak pebangunan generasi berkarakter. Adapun saran dari kegiatan ini adalah perlunya pendapingan yang kontinu dan konsultan pendidikan karakter untuk menghadapi aneka masalah yang muncul dekadensi di masyarkat.

\section{Ucapan Terimakasih}

Terima kasih kami haturkan kepada Sekolah Pascasarjana Universitas Pendidikan Indonesia dan LPPM UPI yang telah memfasilitasi dan mendanai kegiatan pengabdian ini dengan SK Rektor nomor 4857/UN40/PP/2019; serta kepada majelis Taklim desa Cibogo Kabupaten Cianjur yang telah bersidia menyiapkan tempat kaegiatan ini.

\section{DAFTAR PUSTAKA}

Al-Qur' an al-Karim

Hendarman. 2016. "Isu-Isu Kebijakan Pendidikan: PReentasi Sinkronisasi Program Pelibatan Publik dalam Penelitian." Makalah disajikan dan didiskusikan di BAPEDA (Badan Perencanaan dan Pembangunan Daerah) Kota Bandung,pada tanggal 5 Oktober 2018.

Tafsir, A. (2000), Metodologi Pengajaran Agama Islam; Suplemen Modul-modul Program Penyetaraan D-2 GPPAI $S D / M I$, Bandung: Fakultas Tarbiyah IAIN Sunan Gunung Djati.

Komalasari. 2012. "The effect of contextual learning in civic education on students' character development". Asia Pacific Journal of Educators and Education, Vol. 27,87-103, 2012. Tersedia: http://ums.my. Diakses tanggal 25 Februari 2013.

Setyaningrum, Y. dan Husamah 2011. "Optimalisasi Penerapan Pendidikan Karakter di Sekolah Menengah berbasis Keterampilan Proses", Jurnal Penelitian dan Pemikiran Pendidikan, Vol 11, No. 1. Tersedia: http://www.e- 
Jurnal Pengabdian Multidisiplin

journal.umm.ac.id (diakses tangga; 25 Februari 2018).

Sopian, A. 2018. "Internalization of Character Education in the SMPIT As-Syifa Boarding School", SOSIOHUMANIKA: Jurnal Pendidikan Sains, Sosial, dan Kemanusian Volume 11, No.1. hal 47-62.

Susmanto, D. (2012). Implementasi Pendidikan Karakter dalam Proses Pembelajaran (2012). Tersedia [Online]: http://daryosusmanto.blogspot.co.id/201 2/07/implementasi-pendidikankarakter.html. Di akses 20 Februari 2015.

Kemenpora RI. (2009). "Penyajian Data Informasi". [online] http://www.kemenpora.go.id (diakses tanggal 20 Februari 2018) 